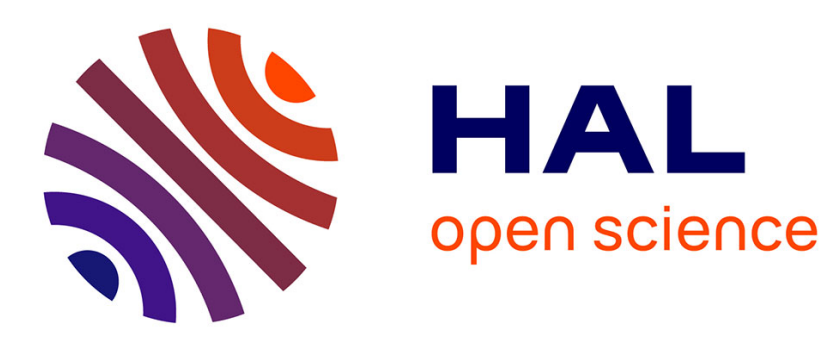

\title{
Transitions between the 3p6ns and 3p6mp states of Ti IV
}

a E Kingston, A Hibbert

\section{To cite this version:}

a E Kingston, A Hibbert. Transitions between the 3p6ns and 3p6mp states of Ti IV. Journal of Physics B: Atomic, Molecular and Optical Physics, 2010, 43 (16), pp.165003. 10.1088/09534075/43/16/165003 . hal-00569824

\section{HAL Id: hal-00569824 \\ https://hal.science/hal-00569824}

Submitted on 25 Feb 2011

HAL is a multi-disciplinary open access archive for the deposit and dissemination of scientific research documents, whether they are published or not. The documents may come from teaching and research institutions in France or abroad, or from public or private research centers.
L'archive ouverte pluridisciplinaire HAL, est destinée au dépôt et à la diffusion de documents scientifiques de niveau recherche, publiés ou non, émanant des établissements d'enseignement et de recherche français ou étrangers, des laboratoires publics ou privés. 


\title{
Transitions between the $3 p^{6}$ ns and $3 p^{6}$ mp states of Ti IV
}

\author{
A E Kingston and A Hibbert \\ Department of Applied Mathematics and Theoretical Physics, \\ Queens University of Belfast, Belfast BT 9 6HH, UK \\ E-mail:a.kingston@qub.ac.uk
}

\begin{abstract}
This paper presents calculations of the oscillator strengths and $A$-values between the $3 \mathrm{p}^{6} \mathrm{~ns}{ }^{2} \mathrm{~S}^{\mathrm{e}}(\mathrm{J}=1 / 2)(\mathrm{n}=4$ to 10$)$ states of Ti IV and the $3 \mathrm{p}^{6} \mathrm{mp}{ }^{2} \mathrm{P}^{\mathrm{e}}(\mathrm{J}=1 / 2$ and $3 / 2)(\mathrm{m}=4$ to 10$)$ states. The calculations were carried out using configuration interaction wave functions in which relativistic effects were included by using the Breit-Pauli approximation. To obtain an indication of the accuracy of the oscillator strengths, calculations were carried out using both the length and velocity formulations of the oscillator strengths. These calculations improve on the accuracy of the earlier work on the excitation of the $3 p^{6} 4 s^{2} \mathrm{~S}$ excited state of Ti IV to the $3 p^{6} \mathrm{mp}{ }^{2} \mathrm{P}^{\mathrm{o}}$ excited states (Kingston and Hibbert 2008) by increasing the number of configurations in the calculations. Comparisons of the present calculations are made with other theoretical calculations..
\end{abstract}




\section{Introduction}

Ti IV is interesting because the $3 p^{6} 3 d$ ground state may be excited by one-electron excitations to the autoionizing (resonance) states $3 \mathrm{p}^{5} 3 \mathrm{~d}^{2}$ and $3 \mathrm{p}^{5} 3 \mathrm{~d} 4 \mathrm{~s}$ which lie above ionization potential of the ground state. These resonances increase the rates of photo-ionization (Schippers et al 2004) and electron ionization (Van Zoest et al 2004) of the $3 \mathrm{p}^{6} 3 \mathrm{~d}$ ground state of Ti IV. They also enhance the rate of photo-recombination in Ti V (Nikolic et al 2009). Kingston and Hibbert have carried out a number of theoretical calculations on many of the basic parameters involved in these processes, such as transition energies, A-values and oscillator strengths. Kingston and Hibbert (2006) used the CIV 3 computer code (Hibbert et al 1991) to obtain transition energies, A-values and oscillator strengths for transitions from the $3 \mathrm{p}^{6} 3 \mathrm{~d}^{2} \mathrm{D}$ ground state of Ti IV to the $3 \mathrm{p}^{6} \mathrm{np}{ }^{2} \mathrm{P}^{0}$ $(\mathrm{n}=4-7), \mathrm{nf}^{2} \mathrm{~F}^{\mathrm{o}}(\mathrm{n}=4-6), 3 \mathrm{p}^{5} 3 \mathrm{~d}^{2}{ }^{2} \mathrm{P}^{\mathrm{o}},{ }^{2} \mathrm{D}^{\mathrm{o}},{ }^{2} \mathrm{~F}^{\mathrm{o}}$ and $3 \mathrm{p}^{5} 3 \mathrm{~d} 4 \mathrm{~s}^{2} \mathrm{P}^{\mathrm{o}}$. These initial calculations only considered transitions to doublet states and were extended by Kingston and Hibbert (2009) to include transitions to the $3 \mathrm{p}^{6} \mathrm{np}{ }^{2} \mathrm{P}^{\mathrm{o}}(\mathrm{n}=4-10), 3 \mathrm{p}^{6} \mathrm{nf}^{2} \mathrm{~F}^{\mathrm{o}}(\mathrm{n}=4-10)$ and all of the doublet and quartet states generated from $3 \mathrm{p}^{5} 3 \mathrm{~d}^{2}$ and $3 \mathrm{p}^{5} 3 \mathrm{~d} 4 \mathrm{~s}$ functions. The results of these calculations are expected to be more accurate than the earlier calculations.

The $3 p^{6} 4 s^{2} S$ excited state of Ti IV is similar to the $3 p^{6} 3 d$ ground state, in that the $3 p^{6} 4 s$ excited state may be excited by one-electron excitation of the $3 p$ electron to the autoionizing (resonance) state $3 \mathrm{p}^{5} 3 \mathrm{~d} 4 \mathrm{~s}^{2} \mathrm{P}^{\mathrm{o}}$ which lies above ionization potential. In order to study this transition Kingston and Hibbert (2008) only used a ground state $3 \mathrm{p}^{6} 4 \mathrm{~s}^{2} \mathrm{~S}$ wave function constructed from orbitals generated by Kingston and Hibbert (2006) and with a variationally determined $4 \mathrm{~s}$ orbital. The excited $3 \mathrm{p}^{6} n \mathrm{p}^{2} \mathrm{P}^{\mathrm{o}}$ ( $\mathrm{n}=4$ to 10 ), $3 \mathrm{p}^{5} 3 \mathrm{~d} 4 \mathrm{~s}^{2} \mathrm{P}^{\mathrm{o}}$ and $3 \mathrm{p}^{5} 3 \mathrm{~d}^{2} \mathrm{P}^{\mathrm{o}}$ wave functions were constructed from orbitals generated by Kingston and Hibbert (2006) plus new $3 \mathrm{p}^{6} \mathrm{np}{ }^{2} \mathrm{P}^{\mathrm{o}}$ ( $\mathrm{n}=8$ to 10$)$ functions. These calculations demonstrated that the transitions from the $3 \mathrm{p}^{5} 3 \mathrm{~d}^{1} \mathrm{P}^{\mathrm{o}} 4 \mathrm{~s}^{2} \mathrm{P}^{\mathrm{o}}(\mathrm{J}=1 / 2$ and $\mathrm{J}=3 / 2)$ states to the ground state $3 \mathrm{p}^{6} 4 \mathrm{~s}^{2} \mathrm{~S}$ have a large A-value of 1.84(11) s $\mathrm{s}^{-1}$. These A-values are in good agreement with the semi empirical calculations of Ryabtsev et al (2005). In the calculations of Kingston and Hibbert (2008) the primary aim was to obtain the A-values of these transitions. These calculations also gave A-values for the $4 \mathrm{~s}$ to $\mathrm{np}$ ( $n=4$ to 10) transitions. By comparing the large differences between the length and velocity oscillator strengths given by these calculations for the $4 \mathrm{~s}$ to $\mathrm{np}$ transitions it is clear that these particular calculations are not sufficiently accurate.

In the present paper the CIV3 code is used to calculate the length and velocity oscillator strengths and A-values for transition rates between $3 \mathrm{p}^{6} \mathrm{~ns}{ }^{2} \mathrm{~S}(\mathrm{n}=4$ to 10$)$ to $3 \mathrm{p}^{6} \mathrm{mp}{ }^{2} \mathrm{P}^{\mathrm{o}}(\mathrm{m}=4$ to 10). As the number of configurations used in the present calculations is significantly larger than the number used in the calculations of Kingston and Hibbert (2008), these new calculations should also improve on the earlier calculations on the $3 \mathrm{p}^{6} 4 \mathrm{~s}^{2} \mathrm{~S}$ to $3 \mathrm{p}^{6} \mathrm{np}{ }^{2} \mathrm{P}^{\mathrm{o}}$ ( $\mathrm{n}=4$ to 10 ) transitions. Section 2 of the paper gives a brief description of the theoretical calculations and also gives the orbitals and configurations used in the calculations. Section 3.1 compares the unmodified calculated energy levels of the ns and np states with experimental values. This section also studies the convergence of the calculated oscillator strengths as the number of excited state functions is increased in the calculation. The oscillator strengths and A-values calculated in the present calculations are given in Section 3.2 where they are compared with earlier calculations. Section 3.3 shows that in certain circumstances the energy of a transition may be obtained 
directly from the length and velocity oscillator strengths. Finally in Section 4 future developments are discussed.

\section{Theoretical Calculations}

The calculations in this paper are similar to those in earlier papers on transitions from the ground $3 d$ states and from the excited 4s state of Ti IV (Kingston and Hibbert 2006, 2008). The calculations were carried out using the CIV 3 computer code (Hibbert et al 1991). This code assumes that the wave functions $\Psi$ are written in configuration interaction (CI) format which, in LSJ coupling, implies that

$$
\Psi(J \pi)=\sum_{i=1}^{M} a_{i} \Phi_{i}\left(\alpha_{i} L_{i} S_{i} J \pi\right)
$$

where $\pi$ denotes parity. In (1), $\alpha_{\mathrm{i}}$ denote other appropriate labeling of the configuration state functions (CSFs) $\Phi_{i}$, for example the orbital occupancy of the electrons. Relativistic effects are included through the following Breit-Pauli operators: spin-orbit, spin-spin, spin-other-orbit, mass correction and Darwin terms. The CI mixing coefficients $a_{\mathrm{i}}$ are the eigenvector components of the Hamiltonian matrix with typical elements $H_{i j}=\left\langle\Phi_{i}|H| \Phi_{j}\right\rangle$, whose eigenvalues $\mathrm{E}_{\mathrm{i}}$ are the calculated energies of the system. The configuration state functions (CSFs) $\Phi_{i}$ are constructed from one-electron orbital functions whose angular momenta are coupled to form total $L_{i} S_{i} J$ in intermediate coupling and which take the form

$$
u(\boldsymbol{r}, \boldsymbol{\sigma})=\frac{1}{r} P_{n l}(r) Y_{l}^{m_{l}}(\theta, \phi) \chi_{m_{s}}(\boldsymbol{\sigma})
$$

The radial functions of the one-electron orbitals are expressed as sums of Slater-type orbitals and are obtained variationally by minimizing an appropriate energy eigenvalue, on the basis of the variational principle (see for example Perkins 1965).

The electric dipole oscillator strengths between the ${ }^{2} \mathrm{~S}^{\mathrm{e}}$ states and ${ }^{2} \mathrm{P}^{\mathrm{o}}$ states are calculated in both the length $f_{l}$ and velocity $f_{v}$ formulations where

$$
(2 J+1) f_{1}=\frac{2}{3} \Delta E_{i j} M_{1} \text { and }(2 J+1) f_{v}=\frac{2}{3} M_{v} / \Delta E_{i j}
$$

$\Delta E_{i j}$ ( in au) is the transition energy between the two states i and j. $M_{1}$ and $M_{v}$ are respectively the length and velocity line strengths where

$$
\mathrm{M}_{\mathrm{l}}=\left|\left(\Psi_{\mathrm{i}}\left(J_{i, j} \pi\right)\left|\Sigma \mathbf{r}_{\mathrm{k}}\right| \Psi_{\mathrm{j}}\left(J_{i, j} \pi\right)\right)\right|^{2} \text { and } \mathrm{M}_{\mathrm{v}}=\left|\left(\Psi_{\mathrm{i}}\left(J_{i, j} \pi\right)\left|\Sigma \nabla_{\mathrm{k}}\right| \Psi_{\mathrm{j}}\left(J_{i, j} \pi\right)\right)\right|^{2}
$$

The summation $k$ is over all electrons. In theoretical calculations the difference between $f_{l}$ and $f_{v}$ is often used as an indication of the accuracy of the results. Generally it is assumed that $\Delta \mathrm{E}_{\mathrm{ij}}$ is accurate and if the calculated values of $f_{l}$ and $f_{v}$ do not agree it is often assumed that $M_{l}$ and/or $M_{v}$ are inaccurate. However if $M_{1}$ and $M_{v}$ are calculated accurately, the calculated values of $f_{l}$ and $f_{v}$ would not be accurate if the transition energy is inaccurate. 
In the present calculations for the CI wave functions $\Psi$ in (1) of the states labeled $3 s^{2} 3 p^{6} n s^{2} S^{e}$ $(\mathrm{J}=1 / 2)(\mathrm{n}=4$ to 10$)$, the LS functions ${ }^{2} \mathrm{~S}^{\mathrm{e}},{ }^{2} \mathrm{P}^{\mathrm{e}},{ }^{4} \mathrm{P}^{\mathrm{e}},{ }^{4} \mathrm{D}^{\mathrm{e}}$ were employed. These functions were generated from the following configurations: $-3 s^{2} 3 p^{6} n s, 3 s 3 p^{6} n s^{2}, 3 s^{2} 3 p^{4} 3 d^{2} n s, 3 s^{2} 3 p^{4} n s^{2} 3 d$, $3 s^{2} 3 p^{4} n s^{2} 4 d, 3 s^{2} 3 p^{4} 3 d 4 d n s(n=4$ to 10$)$ and $3 s^{2} 3 p^{5} 3 d m p(m=4$ to 10). All of the orbitals used to generate these configurations, except the ns orbitals ( $n=5$ to 10 ), are described in an earlier paper (Kingston and Hibbert 2008). To obtain ns orbitals ( $n=5$ to 10), the $4 \mathrm{~s}$ orbital was taken from the earlier paper and the $5 \mathrm{~s}$ orbital was generated by minimizing the energy of the $3 s^{2} 3 p^{6} 5 s$ function in a calculation which included $3 s^{2} 3 p^{6} 4 s+3 s^{2} 3 p^{6} 5 s$ functions. Similarly $6 s$ orbital was obtained by minimizing the energy of the $3 s^{2} 3 p^{6} 6 s$ function in a calculation which included $3 s^{2} 3 p^{6} 4 s+3 s^{2} 3 p^{6} 5 s+3 s^{2} 3 p^{6} 6 s$ functions. This process was repeated for the $7 s, 8 s, 9 s, 10$ s orbitals.

For the $3 \mathrm{~s}^{2} 3 \mathrm{p}^{6} \mathrm{mp}{ }^{2} \mathrm{P}^{\mathrm{o}}(\mathrm{J}=1 / 2)(\mathrm{m}=4$ to 10$)$ states it is necessary to include in (1) the LS functions ${ }^{2} \mathrm{~S}^{\mathrm{o}},{ }^{2} \mathrm{P}^{\mathrm{o}},{ }^{4} \mathrm{P}^{\mathrm{o}},{ }^{4} \mathrm{D}^{\mathrm{o}}$ and for the ${ }^{2} \mathrm{P}^{\mathrm{o}}(\mathrm{J}=3 / 2)$ state to include the ${ }^{2} \mathrm{P}^{\mathrm{o}},{ }^{2} \mathrm{D}^{\mathrm{o}},{ }^{4} \mathrm{~S}^{\mathrm{o}},{ }^{4} \mathrm{P}^{\mathrm{o}},{ }^{4} \mathrm{D}^{\mathrm{o}},{ }^{4} \mathrm{~F}^{\mathrm{o}}$ functions. These functions were generated from the following configurations:- $3 s^{2} 3 p^{6} \mathrm{mp}$, $3 \mathrm{~s}^{2} 3 \mathrm{p}^{4} 3 \mathrm{~d}^{2} \mathrm{mp}, 3 \mathrm{~s} 3 \mathrm{p}^{6} 3 \mathrm{~d} \mathrm{mp}, 3 \mathrm{~s}^{2} 3 \mathrm{p}^{5} 4 \mathrm{f} \mathrm{mp}(\mathrm{m}=4$ to 10$) ; 3 \mathrm{~s}^{2} 3 \mathrm{p}^{5} 3 \mathrm{~d} \mathrm{~ns}(\mathrm{n}=4$ to 10$) ; 3 \mathrm{~s}^{2} 3 \mathrm{p}^{5} 3 \mathrm{~d}^{2}$, $3 s^{2} 3 p^{5} 3 d 4 d, 3 s^{2} 3 p^{5} 4 d 4 s, 3 s^{2} 3 p^{3} 3 d^{4}, 3 s 3 p^{5} 3 d^{3}, 3 s^{2} 3 p^{4} 3 d^{2} 4 f, 3 s^{2} 3 p^{4} 3 d 4 f 4 s$. The orbitals used to generate the ${ }^{2} \mathrm{P}^{0}(\mathrm{~J}=1 / 2)$ and ${ }^{2} \mathrm{P}^{\mathrm{o}}(\mathrm{J}=3 / 2)$ functions are described in an earlier paper on Ti IV (Kingston and Hibbert 2006).

\section{Theoretical oscillator strengths and A-values}

\subsection{Preliminary calculations}

The configuration interaction wave functions, described in the previous section, were used to calculate the transition energies between the $3 p^{6} \mathrm{~ns}^{2} \mathrm{~S}^{\mathrm{e}}(\mathrm{J}=1 / 2)(\mathrm{n}=4$ to 10$)$ and the $3 \mathrm{p}^{6} \mathrm{mp}{ }^{2} \mathrm{P}^{\mathrm{o}}$ $(\mathrm{J}=1 / 2$ and $3 / 2) \quad(\mathrm{m}=4$ to 10$)$ states of Ti IV. The energy levels (in au) from the $3 \mathrm{p}^{6} 4 \mathrm{~s}^{2} \mathrm{~S}^{\mathrm{e}}$ $(\mathrm{J}=1 / 2)$ state to the $3 \mathrm{p}^{6} \mathrm{~ns}{ }^{2} \mathrm{~S}^{\mathrm{e}}(\mathrm{J}=1 / 2)(\mathrm{n}=5$ to 10$)$ and to the $3 \mathrm{p}^{6} \mathrm{mp}{ }^{2} \mathrm{P}^{\mathrm{o}}(\mathrm{J}=1 / 2$ and $3 / 2)$ $(\mathrm{m}=4$ to 10$)$ states of Ti IV, calculated using these configuration interaction wave functions, are given in Table 1. They are compared with the experimental measurements of Ryabtsev et al (2005) and Swensson and Edlen (1974). The energy levels for the $3 p^{6} n{ }^{2} S^{e}(J=1 / 2)(n=9$ and 10) states have not been measured. The energy levels for these states were obtained by extrapolating the $3 \mathrm{p}^{6} \mathrm{~ns}{ }^{2} \mathrm{~S}^{\mathrm{e}} \mathrm{n}=6,7$ and 8 experimental energies.

Table 1 shows that the experimental and theoretical transition energy between 4 s ground state and all of the ns excited states differ consistently by approximately 0.004 au but for the $4 \mathrm{~s}$ to $\mathrm{mp}$ transitions the differences are approximately $0.025 \mathrm{au}$. In an earlier calculation on $4 \mathrm{~s}$ to $\mathrm{mp}$ states (Kingston and Hibbert 2008) the difference between the experimental and theoretical transition energies was less than $0.01 \mathrm{au}$. This increase in the difference between the experimental and theoretical transition energies for the $4 \mathrm{~s}-\mathrm{mp}$ transitions is due to the introduction of $3 \mathrm{~s}^{2} 3 \mathrm{p}^{5} 3 \mathrm{~d} \mathrm{mp}{ }^{2} \mathrm{~S}^{\mathrm{e}}$ functions in the calculations. The earlier paper was chiefly concerned with calculating the large A-values for the $4 \mathrm{~s}$ to $\left[3 \mathrm{p}^{5} 3 \mathrm{~d}^{1} \mathrm{P}^{\mathrm{o}} 4 \mathrm{~s}\right]{ }^{2} \mathrm{P}^{\mathrm{o}}$ states; the present calculations do not change the value of those A-values significantly.

For transitions between highly excited states the differences between transition energies given by theory and experiment are relatively large. For example Table 1 shows that the transition energy for the $7 \mathrm{~s}$ to $7 \mathrm{p}(\mathrm{J}=1 / 2$ to $\mathrm{J}=1 / 2)$ transition obtained by these preliminary theoretical calculations is 0.0439 au which is almost twice as large as the experimental value of $0.0229 \mathrm{au}$. 
For this transition the theoretical transition energy is inaccurate as it is obtained by subtracting two large numbers, the calculated total energy of the $7 \mathrm{~s}$ state, -849.8457 au, and the calculated total energy of the $7 \mathrm{p}$ state, -849.8018 au these give a $7 \mathrm{~s}-7 \mathrm{p}$ transition energy of 0.0439 au.

Tables 2 and 3 contain length $f_{1}$ and velocity $f_{v}$ oscillator strengths obtained for some ( $J=1 / 2$ to $\mathrm{J}=1 / 2$ ) transitions using the wave functions described in the previous section. These calculations can be used to explore errors produced in oscillator strengths by the use of the inaccurate theoretical transition energies in Table 1. The calculations are also used to explore the convergence of calculated oscillator strengths for transitions between excited states, by using an increasing number of state functions in the configuration interaction wave functions (1) in the calculation of the oscillator strengths.

In configuration interaction calculations of the transition rates between excited states of Ti IV a number of different combinations of initial and final wave functions could be employed. For example in a calculation of the $4 \mathrm{~s}$ to $4 \mathrm{p}$ transition rates, results could obtained using only the $4 \mathrm{~s}$ and $4 \mathrm{p}$ state functions in (1), while perhaps more accurate results could be obtained for the $4 \mathrm{~s}$ to $4 p$ transition rates by including only $4 s, 5 s$ and $5 p$ state functions or $4 s$ and $4 p, 5 p$ functions or $4 s$, $5 \mathrm{~s}, 6 \mathrm{~s}$ and $4 \mathrm{p}, 5 \mathrm{p}$ functions etc. In calculations on the $10 \mathrm{~s}$ to $10 \mathrm{p}$ transitions there are a very large number of different combinations of state functions that may have to be used in the configuration functions (1) to give accurate results.

In order to determine the combination of $\mathrm{s}$ state functions with $\mathrm{p}$ state functions which will give consistent values for the transition rates two different approaches was adopted. Table 2 gives the results for one approach in which all of the 4p, 5p, 6p, 7p, 8p, 9p and 10p state functions were used in the configuration interaction function of the $\mathrm{p}$ states. These configuration interaction functions were used in a series of seven calculations. In this table the first calculation, Type 1 a, only the $4 \mathrm{~s}$ function was include with all of the seven p functions; in the second calculation, Type $1 \mathrm{~b}$, only $4 \mathrm{~s}$ and $5 \mathrm{~s}$ functions were included; Type $1 \mathrm{c}$, included $4 \mathrm{~s}, 5 \mathrm{~s}$ and $6 \mathrm{~s}$ functions; Type $1 \mathrm{~d}$, included 4s, 5s, 6s and 7s functions; Type $1 \mathrm{e}$, included 4s, 5s, 6s, 7s and 8s functions; Type $1 \mathrm{f}$, included 4s, 5s, 6s, 7s, 8s and 9s functions; Type $1 \mathrm{~g}$, included 4s, 5s, 6s, 7s, 8s, 9s and 10 s functions. Table 2 gives length $f_{l}$ and velocity $f_{v}$ oscillator strengths for nine transitions obtained from these seven different types of calculation.

In an alternative approach (Table 3 ) all of the $4 \mathrm{~s}, 5 \mathrm{~s}, 6 \mathrm{~s}, 7 \mathrm{~s}, 8 \mathrm{~s}, 9 \mathrm{~s}$ and $10 \mathrm{~s}$ state function were used in a series of seven calculations. In the first calculation, Type $2 \mathrm{a}$, only the $4 p$ state function was include with all of the seven s functions; in the second calculation, Type $2 b$, only $4 p$ and $5 p$ functions were included; Type $2 \mathrm{c}$, included $4 \mathrm{p}, 5 \mathrm{p}$ and $6 \mathrm{p}$ functions; Type $2 \mathrm{~d}$, included $4 \mathrm{p}, 5 \mathrm{p}$, $6 p$ and $7 p$ functions; Type 1 e, included $4 p, 5 p, 6 p, 7 p$ and $8 p$ functions; Type $2 \mathrm{f}$ included $4 p, 5 p$, $6 \mathrm{p}, 7 \mathrm{p}, 8$ pand $9 \mathrm{p}$ functions; Type $2 \mathrm{~g}$, included $4 \mathrm{p}, 5 \mathrm{p}, 6 \mathrm{p}, 8 \mathrm{p}, 7 \mathrm{p}, 9 \mathrm{p}$ and $10 \mathrm{p}$ functions. Table 3 gives length $f_{1}$ and velocity $f_{v}$ oscillator strengths for nine transitions obtained from these seven different types of calculation.

Table 2 shows that for almost all of the transitions considered the oscillator strengths $f_{1}$ tends to a constant limit as the number of s state functions is increased in the CI wave function (1) and similarly the $f_{v}$ oscillator strengths tend to a different limit as the number of $s$ functions is increased. For example the limit of $f_{l}$ for the $7 \mathrm{~s}$ to $7 \mathrm{p}$ transition is 1.33 but the limit of $\mathrm{f}_{\mathrm{v}}$ for the same transition is 3.47(-1). It is important to note that for this transition the large difference between the length and velocity calculations is not due to large errors in the calculation of the length $M_{1}$ and velocity $M_{v}$ line strength (3.a) but is in due to using an inaccurate transition energy $\Delta \mathrm{E}_{\mathrm{ij}}$ given by these initial preliminary calculations in Table 1 . If this inaccurate theoretical transition energy of $\Delta \mathrm{E}_{\mathrm{ij}}=0.0439$ au for the $7 \mathrm{~s}$ to $7 \mathrm{p}$ transition is replaced in (3) by the experimental transition energy $0.0229 \mathrm{au}$, the resulting oscillator strength $\mathrm{f}_{1}$ is 0.694 and the 
resulting $f_{v}$ is 0.665 . This suggests that the values of $M_{1}$ and $M_{v}$ for this transition are not greatly in error. Similarly for the $9 \mathrm{~s}$ to $9 p$ transition Table 2 which gives $f_{1}=3.02$ and $f_{v}=0.271$, by replacing the preliminary transition $\Delta \mathrm{E}_{\mathrm{ij}}=0.03033$ au by the experimental energy $\Delta \mathrm{E}_{\mathrm{ij}}=0.00951$ au gives $f_{1}=0.946$ and $f_{v}=0.865$ which give an estimate of the error in the line strengths $M_{1}$ and $\mathrm{M}_{\mathrm{v}}$ for this transition.

There are a number of interesting patterns in Table 2. For the $4 s$ to $4 p$ transitions $f_{l}$ and $f_{v}$ change very little as the number of ns state functions is increased in the $4 \mathrm{~s} \mathrm{CI}$ wave functions (1). This suggests that for these transitions there is very little increase in the spatial overlap between the $4 \mathrm{~s}$ and $\mathrm{mp}$ states for $\mathrm{m}>4$. A similar situation arises for the $7 \mathrm{~s}$ to $7 \mathrm{p}$ and $9 \mathrm{~s}$ to $9 \mathrm{p}$ transitions, $\mathrm{f}_{\mathrm{l}}$ and $f_{v}$ change very little as the number of ns state functions in the CI wave functions (1) increases. This suggests that for these transitions there is very little increase in the spatial overlap between the $\mathrm{ms}$ and $\mathrm{mp}$ states for $\mathrm{m}>\mathrm{n}$. Similarly for two transitions involving the $9 \mathrm{~s}$ state, $4 \mathrm{p}$ to $9 \mathrm{~s}$ and $7 \mathrm{p}$ to $9 \mathrm{~s}$, the inclusion of the 10s state function has very little effect on the oscillator strengths. Also for the $4 \mathrm{p}$ to $7 \mathrm{~s}$ transition the inclusion of 8,9 , and $10 \mathrm{~s}$ state functions has very little effect on the oscillator strengths. For these six ns to mp transitions, in which all of the seven $\mathrm{p}$ state functions are used in the configuration interaction functions, the length and the velocity results do not change greatly if the $(n+1)$ s state function is included.

The convergence of the $f_{1}$ calculations as the number of ns states are increased in the $4 \mathrm{~s}$ to $7 \mathrm{p}$, $9 p$ and $7 \mathrm{~s}-9 \mathrm{p}$ transitions is not as good as that for the other transitions studied in Table 2. Consider the large variation of the calculated $\mathrm{f}_{1}$ values for one of these transitions, for example, the $4 \mathrm{~s}$ to $7 \mathrm{p}$ transitions, as the number of ns state functions is increased. In these calculations the $7 \mathrm{p}$ CI wave function includes $4,5,6,7,8,9,10 \mathrm{p}$ state functions. The value of $\mathrm{f}_{1}$ changes only a little from the Type 1a calculation to Type 1c calculations, as the number of s state functions is increased from one $4 \mathrm{~s}$ function to three 4, 5, 6s functions. In calculation Type $1 \mathrm{~d}$ the introduction of a $7 \mathrm{~s}$ function greatly reduces the value of $\mathrm{f}_{\mathrm{l}}$. The introduction of a 8 s function ( Type 1e) increases the value of $f_{1}$ to a value which varies very little as $9 s$ and 10 s functions are included in the calculations. This suggests that for the $4 \mathrm{~s}$ to $7 \mathrm{p}$ transition to obtain good overlap between $4 \mathrm{~s}$ and $7 \mathrm{p} \mathrm{CI}$ wave functions, it is necessary to include a $8 \mathrm{~s}$ state function in the $4 \mathrm{~s}$ CI wave function. This is due to the fact that for a given value on $n$, the $n p$ functions are larger than the equivalent ns function at large values of $r$ and to get a good overlap it is necessary to increase the $4 \mathrm{~s}$ CI wave function by including an $8 \mathrm{~s}$ state function. These differences are also accentuated in the length calculations by the fact that the length calculations emphasize large values of $r$ where the overlap between some s and p functions may be small. It is also seen that for these three calculations the velocity calculations converge more rapidly than the length calculations because the velocity matrix element emphasizing the smaller values of $r$ where the $s$ and $p$ functions overlap.

The results given in Table 3 (where all of the 4,5,6,7,8,9,10s functions are included) differ significantly from those in Table 2 ( where all of the 4,5,6,7,8,9,10p functions are included). The oscillator strengths $f_{1}$ and $f_{v}$ for the ns to $m p$ transitions given in Table 3 all converged when $n p$ functions are included in the $\mathrm{p}$ CI wave function. For example both of the oscillator strengths $\mathrm{f}_{1}$ and $\mathrm{f}_{\mathrm{v}}$ for the $4 \mathrm{p}-9 \mathrm{~s}$ transition both converge if $9 \mathrm{p}$ functions are included in the $\mathrm{p}$ CI wave function. Table 3 also that, in general, where all seven s functions are available, the oscillator strength for a particular transition varies very little as the number of $\mathrm{p}$ functions is increased.

\subsection{Comparisons of present calculations from other calculations}

The results in the previous section suggest that many of the line strengths $M_{l}$ and $M_{v}$ obtained in the preliminary calculations are quite accurate and that the difference between the length and 
velocity oscillator strengths are due to inaccuracies in the transition energies. Replacing the calculated transition energies by the accurate experimental energies should give more accurate oscillator strengths for some transitions. In the present calculations of f-values and A-values, the calculated transition energy is replaced by a more accurate experimental transition energy by using the fine tuning process of Hibbert (1996). This is a variant of a procedure of Beck and Nicolaides (1977) (see also Nicolaides 2005). In this process, small adjustments are made in certain diagonal elements of the Hamiltonian matrix in order to bring calculated energy differences into close agreement with experimental energy differences. This ensures that the transition energies, used in this paper to calculate oscillator strengths and A-values, do not differ significantly from the experimental transition energies.

Tables $4 \mathrm{a}, \mathrm{b}, \mathrm{c}, \mathrm{d}, \mathrm{e}, \mathrm{f}, \mathrm{g}$ present calculations of the oscillator strengths and A-values for transitions between the $3 \mathrm{p}^{6} \mathrm{~ns}^{2} \mathrm{~S}^{\mathrm{e}}$ states $(\mathrm{n}=4$ to 10$)$ and the $3 \mathrm{p}^{6} \mathrm{mp}{ }^{2} \mathrm{P}^{\mathrm{o}}(\mathrm{m}=4$ to 10$)$ states of $\mathrm{Ti}$ IV. The wave functions were adjusted using the fine tuning process so that the transition energies in the calculation do not differ significantly from the measurements of Ryabtsev et al (2005). Experimental transition energies are not available for the 9s and 10s state, so the transitions energies for these two states were obtained by extrapolating the energies given by Ryabtsev et al. Both the length $f_{l}$ and velocity $f_{v}$ oscillator strengths are given as the difference between the values of $f_{1}$ and $f_{v}$ is an indicator of the accuracy of the f-value calculations. Generally in Tables $4 \mathrm{a}, \mathrm{b}, \mathrm{c}, \mathrm{d}, \mathrm{e}, \mathrm{f}$ and $\mathrm{g}$ the values of $\mathrm{f}_{\mathrm{l}}$ and $\mathrm{f}_{\mathrm{v}}$ agree to approximately $5 \%$ for $m p-n s$ transitions for $n=m$ or $n>m$. The ratio of $f_{l} / f_{v}$ for the $n s$ to $m p$ transitions decreases very rapidly for small values of $n$ and large values of $m$. For example the ratio $f_{1} / f_{v}$ for the $4 s-5 p$ and $4 \mathrm{~s}-6 \mathrm{p}$ transitions is approximately 0.9 but for the $4 \mathrm{~s}-9 \mathrm{p}$ and $4 \mathrm{~s}-10 \mathrm{p}$ transitions the ratios are 0.5 and 0.03 respectively. For all of the ns to $10 \mathrm{p}$ transitions (except the $10 \mathrm{~s}$ to $10 \mathrm{p}$ transition) $\mathrm{f}_{\mathrm{l}}$ and $\mathrm{f}_{\mathrm{v}}$ do not agree Due to the lack in convergence in the length calculations as demonstrated in Table 2 for the $4 s$ to $9 p$ transition, the $f_{v}$ results are to be preferred to $f_{1}$ results. The velocity calculations are also to be preferred, because for large values of $m$, the $f_{v}$ values decrease approximately as $\left(\mathrm{I}-\Delta \mathrm{E}_{4 \mathrm{~s}-\mathrm{mp}}\right)^{-1.5}$ where $\mathrm{I}$ is the ionization potential of the $4 \mathrm{~s}$ ion and $\Delta \mathrm{E}_{4 \mathrm{~s}-\mathrm{mp}}$ is the excitation energy from the $4 \mathrm{~s}$ state to the $\mathrm{mp}$ states. This hydrogenic behavior is similar to that found in high $\mathrm{m}$ calculations of oscillator strength. Because there are some large inaccuracies in some of the length calculations only the A-value obtained from the velocity calculations are given in Table 4.

Tables $4 \mathrm{a}, \mathrm{b}, \mathrm{c}, \mathrm{d}$, e also compare the A-values calculated in this paper with recent calculations by Ryabtsev et al (2005) and Zhang et al (2008). Ryabtsev et al (2005) have measured the transition energies in Ti IV for transitions from the $3 \mathrm{p}^{6} 4 \mathrm{~s}^{2} \mathrm{~S}^{\mathrm{e}}$ state to the $3 \mathrm{p}^{6} \mathrm{mp}{ }^{2} \mathrm{P}^{\mathrm{o}}(\mathrm{m}=5$ to 10 ) states and from the $3 \mathrm{p}^{6} 4 \mathrm{p}^{2} \mathrm{P}^{\mathrm{o}}$ state to the $3 \mathrm{p}^{6} \mathrm{~ns}{ }^{2} \mathrm{~S}^{\mathrm{e}}$ (n $=5$ to 8 ) states. They have used these energies in a semiempirical calculation to obtain A-values for all of these transitions. Zhang et al (2008) employed the Weakest Bound Electron Potential Model (WBEPM) to obtain the A-values for the nine transitions between the $3 \mathrm{p}^{6} \mathrm{~ns}{ }^{2} \mathrm{~S}^{\mathrm{e}}(\mathrm{n}=4,5,6)$ states and the $3 \mathrm{p}^{6} \mathrm{mp}{ }^{2} \mathrm{P}^{\mathrm{o}}(\mathrm{m}=4,5,6)$ states.

Table $4 \mathrm{a}$ also gives the $\mathrm{f}_{\mathrm{l}}$ and $\mathrm{f}_{\mathrm{v}}$ oscillator strengths for $4 \mathrm{~s}$ to $\mathrm{mp}$ transitions obtained by Kingston and Hibbert (2008). This calculation did not include higher ns states and as demonstrated in Table 2 this gives inaccurate results at high values of $\mathrm{m}$. There is much better agreement between $f_{1}$ and $f_{v}$ for $4 s$ to $m p$ transitions in the present calculations at small values of $\mathrm{m}$; this is due to the introduction $3 \mathrm{~s}^{2} 3 \mathrm{p}^{5} 3 \mathrm{~d} \mathrm{~m} \mathrm{~m}^{2} \mathrm{~S}^{\mathrm{e}} \mathrm{CI}$ wave functions in the calculations

There is some agreement among the A-values calculated in this paper and those calculated by Zhang et al and Ryabtsev et al. but there are also some major disagreements. The WBEPM 
A-values calculations given by Zhang et al follow the pattern similar to that found in the calculations given in Table 2. This table shows that in the preliminary calculations of the f-values for $\mathrm{ns}$ to $\mathrm{mp}$ transitions converge to their final converged value if $\mathrm{n}$ equals $\mathrm{m}$. If $\mathrm{n}$ is not equal to $\mathrm{m}$ then in order to obtain a converged value of the oscillator strength it is necessary to include both $\mathrm{s}$ and $\mathrm{p}$ functions up to the greater of $\mathrm{n}$ and $\mathrm{m}$. The present calculations and those of Zhang $e t$ $a l$ are in good agreement for the $4 \mathrm{~s}-4 \mathrm{p}, 6 \mathrm{~s}-6 \mathrm{p}$ and $6 \mathrm{~s}-6 \mathrm{p}$ transitions where $\mathrm{n}=\mathrm{m}$. However for the $4 \mathrm{~s}-5 \mathrm{p}$ and $4 \mathrm{~s}-6 \mathrm{p}$ transitions where $\mathrm{n}$ is not equal to $\mathrm{m}$ the two calculations differ by a factor of 2 or more.

The difference between the present A-values and those of Ryabtsev et al for the transitions $4 \mathrm{~s}-\mathrm{mp}(\mathrm{m}=5$ to 10$)$ decreases continuously from approximately $30 \%$ for the $4 \mathrm{~s}-5 \mathrm{p}$ transition, $20 \%$ for the $4 \mathrm{~s}-7 \mathrm{p}$ transition to $4 \%$ for the $4 \mathrm{~s}-10 \mathrm{p}$ transition (except for the $4 \mathrm{~s}-8 \mathrm{p}$ transition where the A-value of Ryabtsev et al only differ slightly from their A-value for 4s-9p transition). There is a similar pattern for the $4 \mathrm{p}$-ns $(\mathrm{n}=5$ to 8$)$ transitions The difference in the present A-values and those of Ryabtsev et al decreases from $15 \%$ for the $4 \mathrm{p}-6 \mathrm{~s}$ transition to $8 \%$ for the $4 \mathrm{p}-7 \mathrm{~s}$ transition and to $2 \%$ for the $4 \mathrm{p}-8 \mathrm{~s}$ transition. Since the methods used in the present theoretical calculations of A-values differ greatly from the methods used in the semiempirical calculations of Ryabtsev et $a l$, it is very difficult to ascertain why the agreement between the two calculations is very good for transitions to highly excited states but the agreement is less good low lying states. One possible explanation is the inclusion in the present work of much more correlation contributions ;these are less important for the higher Rydberg states

Although there is not complete agreement between the A-values given by the present calculations and those given by the semiempirical calculations of Ryabtsev et al (2005), the agreement is very satisfying, taking into consideration the very different methods used in the two calculations.

\subsection{Comments on length and velocity oscillator strengths}

The length $f_{1}$ and velocity $f_{v}$ formulation of the oscillator strengths are given by (3), where $\Delta E$ is the transition energy and $\mathrm{M}_{1}$ and $\mathrm{M}_{\mathrm{v}}$ are the length and velocity line strengths. If $\Delta \mathrm{E}$ and $\mathrm{M}_{1}$ and $M_{v}$ are accurate $f_{1}$ and $f_{v}$ are equal and so the difference between $f_{1}$ and $f_{v}$ is often used as an indication of the accuracy of the calculated oscillator strengths. In most calculations it is assumed that the transition energy is calculated more accurately than the length and velocity matrix elements. However in the preliminary ab initio calculations (Section 3.1), it is seen that some of the very small transition energies did not agree with the experimental transition energies. Tables 2 and 3 show that using the inaccurate energies given by the preliminary calculations can lead to some very large differences in the length and velocity oscillator strengths. However for many transitions there is very good agreement between the length and velocity calculations when these inaccurate transition energies are replaced by accurate experimental transition energies.

It is interesting to study the results that are obtained when inaccurate calculated energies are replaced by accurate experimental energies in calculated oscillator strengths. Consider a calculation in which it is assumed that the transition energy $\Delta \mathrm{E}$ and the length and velocity oscillator strengths $f_{l}$ and $f_{v}$ are inaccurate but that the line strengths $M_{l}$ and $M_{v}$ are accurate. If the inaccurate transition energy $\Delta E$ in (3) is replaced by an accurate transition energy $\Delta E^{t}$ in $f_{l}$ and $f_{v}$, this would give accurate oscillator strengths $\mathrm{f}_{1}^{\mathrm{a}}$ and $\mathrm{f}_{\mathrm{v}}{ }^{\mathrm{a}}$ which are given by

$(2 \mathrm{~J}+1) \mathrm{f}_{1}^{\mathrm{a}}=(2 \mathrm{~J}+1)\left(\Delta \mathrm{E}^{\mathrm{t}} / \Delta \mathrm{E}\right) \mathrm{f}_{\mathrm{l}}=\frac{2}{3} \Delta \mathrm{E}^{\mathrm{t}} \mathrm{M}_{\mathrm{l}}$ and $(2 \mathrm{~J}+1) \mathrm{f}_{\mathrm{v}}{ }^{\mathrm{a}}=(2 \mathrm{~J}+1)\left(\Delta \mathrm{E} / \Delta \mathrm{E}^{\mathrm{t}}\right) \mathrm{f}_{\mathrm{v}}=\frac{2}{3} \mathrm{M}_{\mathrm{v}} / \Delta \mathrm{E}^{\mathrm{t}}$ 
so, since $\mathrm{f}_{1}^{\mathrm{a}}$ and $\mathrm{f}_{\mathrm{v}}{ }^{\mathrm{a}}$ are now equal

$$
\left(\Delta \mathrm{E}^{\mathrm{t}} / \Delta \mathrm{E}\right)^{2}=\mathrm{f}_{\mathrm{v}} / \mathrm{f}_{\mathrm{l}} \quad \text { or } \quad \Delta \mathrm{E}^{\mathrm{t}}=\Delta \mathrm{E}\left(\mathrm{f}_{\mathrm{v}} / \mathrm{f}_{\mathrm{l}}\right)^{1 / 2}
$$

Hence in a calculation in which $\mathrm{M}_{1}$ and $\mathrm{M}_{\mathrm{v}}$ are accurate but $\Delta \mathrm{E}$ is inaccurate, a more accurate value of the transition energy $\Delta E^{t}$ may be obtained from the calculated values of $f_{l}$ and $f_{v}$ and the inaccurate $\Delta \mathrm{E}$, using (5). It is also seen that in such a situation the oscillator $\mathrm{f}^{\mathrm{t}}$ obtained using $\Delta \mathrm{E}^{\mathrm{t}}$ with $\mathrm{M}_{1}$ and $\mathrm{M}_{\mathrm{v}}$ is given by

$$
f^{t}=\left(f_{l} f_{v}\right)^{1 / 2}
$$

Table 5 gives the transition energies $\Delta \mathrm{E}^{\mathrm{t}}$ and the oscillator strengths $\mathrm{f}^{\mathrm{t}}$ for $\mathrm{J}=1 / 2$ to $\mathrm{J}=1 / 2$ transitions in Ti IV between the ns and $m p$ states, $n=m$ and $n=4$ to 10 , and also the oscillator strengths for the $m p$ to $n s$ transitions with $m=4$ to 9 and $n=m+1$. The expressions given in (5) for $\Delta E^{t}$ and (6) for $f^{t}$ were obtained from the $\Delta E$ values and the oscillator strengths $f_{l}$ and $f_{v}$ given by the preliminary calculations discussed in Section 3.1. These calculated transition energies and oscillator strengths are compared with the experimental transition $\Delta \mathrm{E}^{\mathrm{e}}$ and the calculated oscillator strengths $\mathrm{f}_{\mathrm{v}}^{\mathrm{c}}$ given in Tables $4 \mathrm{a}, \mathrm{b}, \mathrm{c}, \mathrm{d}, \mathrm{e}, \mathrm{f}$, and $\mathrm{g}$. The agreement, for example, between the experimental transition energy $\Delta \mathrm{E}^{\mathrm{e}}$ and the transition energy given by (5) for the $9 \mathrm{p}$ to $10 \mathrm{~s}$ transition is remarkable. In this case the ratio given by the initial calculation (Section 3.1) for $\mathrm{f}^{\mathrm{v}} / \mathrm{f}^{\mathrm{l}}$ is 36620 . This combines with transition energy given by the initial calculations $\Delta \mathrm{E}=0.0001092$ au in (6) to give an energy $\Delta \mathrm{E}^{\mathrm{t}}=0.02089 \mathrm{au}$ which is in good agreement with the experimental energy $\Delta \mathrm{E}^{\mathrm{e}}=0.02082 \mathrm{au}$.

\section{Conclusions}

This paper gives calculated values of the transition energies and the length and velocity oscillator strengths for transitions between the $n s$ and $m p$ states of Ti IV for $n=4$ to 10 and $m=4$ to 10. The paper highlights a number of problems in these theoretical calculations. One of the major problems is the calculation of the very small transition energies which arise in $\mathrm{ns}$ to $\mathrm{mp}$ transitions in which $\mathrm{n}=\mathrm{m}$, or in which $\mathrm{n}$ and $\mathrm{m}$ are almost equal. For example the experimental transition energy $\Delta \mathrm{E}(10 \mathrm{~s}$ to $10 \mathrm{p})$ is 0.00666 au but the transition energy obtained in these calculations is $0.02751 \mathrm{au}$. This problem can be overcome using the fine tuning process but without experimental transition energies these calculations would not have been possible. It would be interesting to use the results described in section 3.3 to explore the possibility of obtaining better theoretical transition energies if no experimental results are available.

The present calculations also indicate that if $\mathrm{n}$ is small the $\mathrm{ns}$ to $\mathrm{mp}$ length oscillator strengths decrease more rapidly than the velocity oscillator strengths as $m$ increases. It may be possible to lessen this rapid decrease by using more $\mathrm{C}$ I functions or by using a single pseudo-state to take account of all higher states. Some experimental measurements of the A-values of any of the ns to $\mathrm{mp}$ transitions in Ti IV would be useful.

\section{Acknowledgements}

We are pleased to acknowledge the support of a PPARC Grant PP/D00103X/1. 


\section{References}

Beck D R and Nicolaides C A 1977 Phys. Lett. A61 227-9

Hibbert A 1996 Physica Scripta T65 104-09

Hibbert A, Glass R and Froese Fischer C 1991 Comput. Phys. Commun.. 64 455-72

Kingston A E and Hibbert A 2006 J. Phys. B: At. Mol. Phys. 39 2217-2230

Kingston A E and Hibbert A 2008 J. Phys. B: At. Mol. Phys. 41 1-4

Kingston A E and Hibbert A 2009 J. Phys. B: At. Mol. Phys. 42 1-8

Nicolaides C A 2005 Int. J. Quantum Chem. 102 250-64

Nikolic D, Gorczyca T W and Badnell N 2009 Phys. Rev. A.79 102703

Perkins J F 1965 J. Chem. Phys. 42 3927-30

Ryabtsev A N, Churilov S S and Kononov E Ya 2005 Optics and Spectroscopy 98 519-27

Schippers S et al 2004 J. Phys. B: At. Mol. Phys. 37 L209-16

Swensson W and Edlen B 1974 Physica Scripta.. 9 335-337

Van Zoest T, Knopp H, Jacobi J, Schippers S, Phaneuf R A and Muller 2004 J. Phys. B: At. Mol. Phys. 39 4387-95

Zhang T Y, Zheng N W and Ma D X A 2008 Int.J. Quant. Chem.109 145-159 
Table1. Experimental energy levels (in au) compared with preliminary ab initio theoretical energy levels (in au) from the $3 \mathrm{p}^{6} 4 \mathrm{~s}^{2} \mathrm{~S}^{\mathrm{e}}(\mathrm{J}=1 / 2)$ to the $3 \mathrm{p}^{6} \mathrm{~ns}{ }^{2} \mathrm{~S}^{\mathrm{e}}(\mathrm{J}=1 / 2)(\mathrm{n}=5$ to 10$)$ states and to the $3 \mathrm{p}^{6} \mathrm{mp}{ }^{2} \mathrm{P}^{\mathrm{o}}$ $(\mathrm{J}=1 / 2$ and $3 / 2)(\mathrm{m}=4$ to 10$)$ of Ti IV.

\begin{tabular}{|c|c|c|c|c|c|c|c|}
\hline & $\Delta \mathrm{E}(\mathrm{au})$ & $\Delta \mathrm{E}(\mathrm{au})$ & & $\Delta \mathrm{E}(\mathrm{au})$ & $\Delta \mathrm{E}(\mathrm{au})$ & $\Delta \mathrm{E}(\mathrm{au})$ & $\Delta \mathrm{E}(\mathrm{au})$ \\
\hline & Ryabtsev & Present & & Ryabtsev & Present & Ryabtsev & Present \\
\hline & Experiment & Theory & & Experiment & Theory & Experiment & Theory \\
\hline $2 \mathrm{~J}+1$ & 2 & 2 & & 2 & 2 & 4 & 4 \\
\hline $4 \mathrm{~s}$ & 0.0 & 0.0 & $4 p$ & $0.21658^{\mathrm{a}}$ & 0.23658 & $0.2203^{\mathrm{a}}$ & 0.24047 \\
\hline $5 s$ & 0.60152 & 0.60549 & $5 p$ & 0.68445 & 0.70967 & 0.68587 & 0.71136 \\
\hline $6 s$ & 0.84501 & 0.84910 & $6 p$ & 0.88547 & 0.91058 & 0.88618 & 0.91160 \\
\hline $7 \mathrm{~s}$ & 0.96873 & 0.97261 & $7 p$ & 0.99163 & 1.01647 & 0.99208 & 1.01725 \\
\hline $8 \mathrm{~s}$ & 1.04028 & 1.04403 & $8 p$ & 1.05444 & 1.07914 & 1.05465 & 1.07978 \\
\hline $9 \mathrm{~s}$ & 1.08526 & 1.08905 & $9 p$ & 1.09477 & 1.11939 & 1.09493 & 1.11996 \\
\hline $10 \mathrm{~s}$ & 1.11559 & 1.11922 & $10 p$ & 1.12225 & 1.14679 & 1.12231 & 1.14731 \\
\hline
\end{tabular}

Footnote a:Swenssen and Edlen (1974) 
Table 2. Length $f_{1}$ and velocity $f_{v}$ oscillator strengths calculated using all of the $4 p, 5 p, 6 p, 7 p, 8 p, 9 p$ and $10 \mathrm{p}$ functions. The preliminary ab initio calculated transition energies are used in these calculations. The Type of calculation is described in the text.

\begin{tabular}{|c|c|c|c|c|c|c|c|}
\hline Calculation & Type 1a & Type 1b & Type 1c & Type 1d & Type 1e & Type 1f & Type $1 \mathrm{~g}$ \\
\hline & $4 s$ & $4,5 \mathrm{~s}$ & $4,5,6 \mathrm{~s}$ & $4,5,6,7 \mathrm{~s}$ & $\begin{array}{c}4,5,6,7 \\
, 8 \mathrm{~s} \\
\end{array}$ & $\begin{array}{r}4,5,6,7 \\
, 8,9 \mathrm{~s} \\
\end{array}$ & $\begin{array}{l}4,5,6,7 \\
, 8,9,10 \mathrm{~s}\end{array}$ \\
\hline $4 s-4 p f_{1}$ & $3.11(-1)$ & $3.11(-1)$ & $3.10(-1)$ & $3.10(-1)$ & $3.10(-1)$ & $3.10(-1)$ & $3.09(-1)$ \\
\hline $4 \mathrm{~s}-4 \mathrm{p} \mathrm{f}_{\mathrm{v}}$ & $2.33(-1)$ & $2.38(-1)$ & $2.40(-1)$ & $2.42(-1)$ & $2.42(-1)$ & $2.43(-1)$ & $2.43(-1)$ \\
\hline $4 p-7 s \quad f_{l}$ & & & & $9.09(-3)$ & $9.22(-3)$ & $9.28(-3)$ & $9.30(-3)$ \\
\hline $4 p-7 s \quad f_{v}$ & & & & $9.63(-3)$ & $9.79(-3)$ & $9.86(-3)$ & $9.90(-3)$ \\
\hline $4 \mathrm{p}-9 \mathrm{~s} \quad \mathrm{f}_{1}$ & & & & & & $2.46(-3)$ & $2.49(-3)$ \\
\hline $4 p-9 s \quad f_{v}$ & & & & & & $2.81(-3)$ & $2.86(-3)$ \\
\hline $4 \mathrm{~s}-7 \mathrm{p} \mathrm{f} \mathrm{f}_{1}$ & $4.71(-3)$ & $4.86(-3)$ & $5.17(-3)$ & $1.97(-3)$ & $3.14(-3)$ & $3.42(-3)$ & $3.53(-3)$ \\
\hline $4 s-7 p f_{v}$ & $5.11(-3)$ & $5.21(-3)$ & $5.28(-3)$ & $4.03(-3)$ & $3.93(-3)$ & $3.89(-3)$ & $3.88(-3)$ \\
\hline $7 \mathrm{~s}-7 \mathrm{p} \mathrm{f_{1 }}$ & & & & 1.35 & 1.33 & 1.33 & 1.33 \\
\hline $7 \mathrm{~s}-7 \mathrm{p} \mathrm{f_{v }}$ & & & & $3.32(-1)$ & $3.42(-1)$ & $3.46(-1)$ & $3.47(-1)$ \\
\hline $7 \mathrm{p}-9 \mathrm{~s} \quad \mathrm{f}_{1}$ & & & & & & $4.58(-2)$ & $4.64(-2)$ \\
\hline $7 p-9 s \quad f_{v}$ & & & & & & $7.60(-2)$ & $7.73(-2)$ \\
\hline $4 \mathrm{~s}-9 \mathrm{p} \mathrm{f}_{1}$ & $1.88(-3)$ & $1.94(-3)$ & $2.00(-3)$ & $2.10(-3)$ & $2.23(-3)$ & $2.49(-4)$ & $9.02(-4)$ \\
\hline $4 s-9 \mathrm{p}_{\mathrm{v}}$ & $1.98(-3)$ & $1.99(-3)$ & $2.01(-3)$ & $2.03(-3)$ & $2.06(-3)$ & $1.62(-3)$ & $1.59(-3)$ \\
\hline $7 \mathrm{~s}-9 \mathrm{p} \mathrm{f}_{1}$ & & & & $4.94(-3)$ & $5.16(-3)$ & $1.96(-3)$ & $2.79(-3)$ \\
\hline $7 \mathrm{~s}-9 \mathrm{p} \mathrm{f}_{\mathrm{v}}$ & & & & $4.08(-3)$ & $4.18(-3)$ & $2.78(-3)$ & $2.62(-3)$ \\
\hline $9 \mathrm{~s}-9 \mathrm{p} \mathrm{f} \mathrm{f}_{1}$ & & & & & & 3.06 & 3.02 \\
\hline $9 \mathrm{~s}-9 \mathrm{p} \mathrm{f} \mathrm{f}_{\mathrm{v}}$ & & & & & & $2.62(-1)$ & $2.71(-1)$ \\
\hline
\end{tabular}


Table 3. Length $f_{1}$ and velocity $f_{v}$ oscillator strengths calculated using all of the $4 s, 5 s, 6 s, 7 s, 8 s, 9 s$ and $10 s$ functions. The preliminary ab initio calculated transition energies are used in these calculations. The Type of calculation is described in the text.

\begin{tabular}{|c|c|c|c|c|c|c|c|}
\hline Calculation & Type $2 \mathrm{a}$ & Type $2 b$ & Type 2c & Type $2 \mathrm{~d}$ & Type $2 \mathrm{e}$ & Type $2 \mathrm{f}$ & Type $2 \mathrm{~g}$ \\
\hline & $4 p$ & $4,5 p$ & $4,5,6 \mathrm{p}$ & $4,5,6,7 p$ & $\begin{array}{c}4,5,6,7 \\
, 8 \mathrm{p}\end{array}$ & $\begin{array}{c}4,5,6,7,8 \\
, 9 \mathrm{p}\end{array}$ & $\begin{array}{c}4,5,6,7,8 \\
, 9,10 \mathrm{p}\end{array}$ \\
\hline $4 \mathrm{~s}-4 \mathrm{p} \mathrm{f}_{1}$ & $3.13(-1)$ & $3.11(-1)$ & $3.10(-1)$ & $3.10(-1)$ & $3.10(-1)$ & $3.10(-1)$ & $3.09(-1)$ \\
\hline $4 \mathrm{~s}-4 \mathrm{p} \mathrm{f}_{\mathrm{v}}$ & $2.49(-1)$ & $2.46(-1)$ & $2.45(-1)$ & $2.44(-1)$ & $2.43(-1)$ & $2.43(-1)$ & $2.43(-1)$ \\
\hline $4 \mathrm{~s}-7 \mathrm{p} \mathrm{f}$ & & & & $3.41(-3)$ & $3.50(-3)$ & $3.53(-3)$ & $3.53(-3)$ \\
\hline $4 \mathrm{~s}-7 \mathrm{p} \mathrm{f_{v }}$ & & & & $3.69(-3)$ & $3.81(-3)$ & $3.85(-3)$ & $3.88(-3)$ \\
\hline $4 \mathrm{~s}-9 \mathrm{p} \mathrm{f}_{1}$ & & & & & & $8.95(-4)$ & $9.02(-4)$ \\
\hline $4 s-9 \mathrm{p} \mathrm{f}_{\mathrm{v}}$ & & & & & & $1.54(-3)$ & $1.59(-3)$ \\
\hline $4 p-7 s \quad f_{1}$ & $1.03(-2)$ & $1.15(-2)$ & $1.59(-2)$ & $9.11(-3)$ & $9.20(-3)$ & $9.27(-3)$ & $9.30(-3)$ \\
\hline $4 p-7 s \quad f_{v}$ & $9.84(-3)$ & $1.03(-2)$ & $1.07(-2)$ & $9.95(-3)$ & $9.93(-3)$ & $9.91(-3)$ & $9.90(-3)$ \\
\hline $7 \mathrm{~s}-7 \mathrm{p} \mathrm{f_{1 }}$ & & & & 1.33 & 1.32 & 1.33 & 1.33 \\
\hline $7 \mathrm{~s}-7 \mathrm{p} \mathrm{f_{v }}$ & & & & $3.51(-1)$ & $3.49(-1)$ & $3.48(-1)$ & $3.47(-1)$ \\
\hline $7 \mathrm{~s}-9 \mathrm{p} \mathrm{f}_{1}$ & & & & & & $2.72(-3)$ & $2.79(-3)$ \\
\hline $7 \mathrm{~s}-9 \mathrm{p} \mathrm{f_{v }}$ & & & & & & $2.53(-3)$ & $2.62(-3)$ \\
\hline $4 p-9 s \quad f_{1}$ & $2.91(-3)$ & $3.13(-3)$ & $3.49(-3)$ & $4.13(-3)$ & $7.18(-3)$ & $2.48(-3)$ & $2.50(-3)$ \\
\hline $4 p-9 s \quad f_{v}$ & $2.77(-3)$ & $2.88(-3)$ & $2.95(-3)$ & $3.02(-3)$ & $3.11(-3)$ & $2.87(-3)$ & $2.87(-3)$ \\
\hline $7 p-9 s \quad f_{1}$ & & & & $4.58(-2)$ & $5.54(-2)$ & $4.64(-2)$ & $4.64(-2)$ \\
\hline $7 p-9 s \quad f_{v}$ & & & & $7.66(-2)$ & $8.16(-2)$ & 7.74(-2) & $7.73(-2)$ \\
\hline $9 \mathrm{~s}-9 \mathrm{p} \mathrm{f} \mathrm{f}_{1}$ & & & & & & 3.07 & 3.02 \\
\hline $9 \mathrm{~s}-9 \mathrm{p} \mathrm{f} \mathrm{f}_{\mathrm{v}}$ & & & & & & $2.72(-1)$ & $2.71(-1)$ \\
\hline
\end{tabular}


Table 4. Transition energies $\Delta E$ (in au ) and calculated length $f_{1}$ and velocity $f_{v}$ oscillator strengths for optically allowed transitions between the $3 \mathrm{p}^{6} \mathrm{~ns}^{2} \mathrm{~S}^{\mathrm{e}}(\mathrm{J}=1 / 2)(\mathrm{n}=4$ to 10$)$ states and the $3 \mathrm{p}^{6} \mathrm{mp}{ }^{2} \mathrm{P}^{\mathrm{o}}(\mathrm{J}=1 / 2$ and $3 / 2)(m=4$ to 10$)$ states of Ti IV. The A-values $\left(\mathrm{s}^{-1}\right)$ calculated using $\mathrm{f}_{\mathrm{v}}$ are also given. Where possible the present A-value calculations are compared with the calculations of Ryabtsev et al (2005) and Zhang et al (2008). In the tables the notation $\mathrm{a}(\mathrm{b})=\mathrm{a} \times 10^{\mathrm{b}}$ is used. In these calculations the fine tuning process (Hibbert 1996) was used to ensure that the transition energies used in these calculations are in good agreement with the experimental transition energies.

Table 4 a. Caption as for Table 4 but for the $3 p^{6} 4 s^{2} S^{e}(J=1 / 2)$ state.

\begin{tabular}{|c|c|c|c|c|c|c|c|c|c|}
\hline & & \multicolumn{4}{|c|}{ Present calculations } & \multicolumn{2}{|c|}{$\begin{array}{l}\text { Kingston and } \\
\text { Hibbert (2008) }\end{array}$} & \multirow{2}{*}{$\begin{array}{c}\begin{array}{r}\text { Zhang } \\
\text { et al }\end{array} \\
\text { A- } \\
\text { values }\end{array}$} & \multirow{2}{*}{$\begin{array}{l}\begin{array}{l}\text { Ryabtsev } \\
\text { et al }\end{array} \\
\begin{array}{c}\text { A- } \\
\text { values }\end{array} \\
\end{array}$} \\
\hline & $2 \mathrm{~J}+1$ & $\Delta \mathrm{E}$ & $\mathrm{f}_{1}$ & $\mathrm{f}_{\mathrm{v}}$ & $\begin{array}{l}\text { A- } \\
\text { values }\end{array}$ & $\mathrm{f}_{1}$ & $f_{v}$ & & \\
\hline $4 s--4 p$ & $2-2$ & 0.2166 & $2.83(-1)$ & $2.68(-1)$ & $4.04(8)$ & $3.00(-1)$ & $1.32(-1)$ & $4.68(8)$ & - \\
\hline $4 s--4 p$ & $2-4$ & 0.2203 & $5.77(-1)$ & $5.29(-1)$ & $4.12(8)$ & $6.10\{-1\}$ & $2.63(-1)$ & $4.93(8)$ & - \\
\hline $4 s--5 p$ & $2-2$ & 0.6845 & $1.33(-2)$ & $1.37(-2)$ & $2.07(8)$ & $1.45(-2)$ & $2.21(-2)$ & $1.07(8)$ & $1.47(8)$ \\
\hline $4 s-5 p$ & $2-4$ & 0.6859 & $2.45(-2)$ & $2.45(-2)$ & $2.01(8)$ & $2.67(-2)$ & $4.31(-2)$ & $9.51(7)$ & $1.48(8)$ \\
\hline $4 s--6 p$ & $2-2$ & 0.8855 & $6.75(-3)$ & $7.25(-3)$ & $1.83(8)$ & $8.56(-3)$ & $9.98(-3)$ & $4.20(7)$ & $1.40(8)$ \\
\hline $4 s--6 p$ & $2-4$ & 0.8862 & $1.28(-2)$ & $1.43(-2)$ & $1.81(8)$ & $1.63(-2)$ & $1.98(-2)$ & $3.72(7)$ & $1.40(8)$ \\
\hline $4 s--7 p$ & $2-2$ & 0.9916 & $3.44(-3)$ & $3.97(-3)$ & $1.25(8)$ & $4.79(-3)$ & $5.12(-3)$ & & $9.75(7)$ \\
\hline $4 s--7 p$ & $2-4$ & 0.9921 & $6.58(-3)$ & $7.89(-3)$ & $1.25(8)$ & $9.22(-3)$ & $1.02(-2)$ & & $9.73(7)$ \\
\hline $4 s--8 p$ & $2-2$ & 1.0544 & $1.86(-3)$ & $2.47(-3)$ & $8.82(7)$ & $2.97(-3)$ & $3.07(-3)$ & & $6.05(7)$ \\
\hline $4 s--8 p$ & $2-4$ & 1.0547 & $3.60(-3)$ & $4.95(-3)$ & $8.85(7)$ & $5.76(-3)$ & $6.19(-3)$ & & $6.08(7)$ \\
\hline $4 s--9 p$ & $2-2$ & 1.0948 & $8.91(-4)$ & $1.62(-3)$ & $6.25(7)$ & $1.95(-3)$ & $1.97(-3)$ & & $5.95(7)$ \\
\hline 4s--9p & $2-4$ & 1.0949 & $1.70(-3)$ & $3.27(-3)$ & $6.39(7)$ & $3.80(-3)$ & $4.00(-3)$ & & $6.10(7)$ \\
\hline $4 \mathrm{~s}-10 \mathrm{p}$ & $2-2$ & 1.1222 & $2.79(-5)$ & $1.11(-3)$ & $4.48(7)$ & $1.32(-3)$ & $1.32(-3)$ & & $4.29(7)$ \\
\hline $4 \mathrm{~s}-10 \mathrm{p}$ & $2-4$ & 1.1223 & $6.35(-5)$ & $2.25(-3)$ & $4.56(7)$ & $2.60(-3)$ & $2.70(-3)$ & & $4.28(7)$ \\
\hline
\end{tabular}


15

Table 4 b. Caption as for Table 4 but for the $3 p^{6} 5 s^{2} S^{e}(J=1 / 2)$ state.

\begin{tabular}{|l|l|l|l|l|l|l|}
\hline & \multicolumn{5}{|c|}{ Present calculations } & Zhang et al \\
\hline & $2 \mathrm{~J}+1$ & $\Delta \mathrm{E}$ & $\mathrm{f}_{1}$ & $\mathrm{f}_{\mathrm{v}}$ & A-values & A-values \\
\hline & & & & & & \\
\hline $4 \mathrm{p}-5 \mathrm{~s}$ & $2-2$ & 0.3849 & $1.55(-1)$ & $1.58(-1)$ & $7.52(8)$ & $5.56(8)$ \\
\hline $4 \mathrm{p}-5 \mathrm{~s}$ & $4-2$ & 0.3812 & $1.58(-1)$ & $1.59(-1)$ & $1.48(9)$ & $1.12(8)$ \\
\hline & & & & & & \\
\hline $5 \mathrm{~s}--5 \mathrm{p}$ & $2-2$ & $8.293(-2)$ & $4.44(-1)$ & $4.29(-1)$ & $9.48(7)$ & $9.80(7)$ \\
\hline & & & $9.01(-1)$ & $8.55(-1)$ & $9.77(7)$ & $1.03(8)$ \\
\hline $5 \mathrm{~s}--5 \mathrm{p}$ & $2-4$ & $8.435(-2)$ & & & & \\
\hline $5 \mathrm{~s}--6 \mathrm{p}$ & $2-2$ & 0.2840 & $6.00(-3)$ & $6.61(-3)$ & $1.71(7)$ & $2.00(7)$ \\
\hline & & 0.2847 & $1.06(-2)$ & $1.23(-2)$ & $1.60(7)$ & $1.75(7)$ \\
\hline $5 \mathrm{~s}--7 \mathrm{p}$ & $2-2$ & 0.3901 & $3.39(-3)$ & $3.86(-3)$ & $1.89(7)$ & \\
\hline $5 \mathrm{~s}--7 \mathrm{p}$ & $2-4$ & 0.3906 & $6.22(-3)$ & $7.41(-3)$ & $1.81(7)$ & \\
\hline & & & & & & \\
\hline $5 \mathrm{~s}--8 \mathrm{p}$ & $2-2$ & 0.4529 & $1.79(-3)$ & $2.27(-3)$ & $1.50(7)$ & \\
\hline $5 \mathrm{~s}--8 \mathrm{p}$ & $2-4$ & 0.4531 & $3.33(-3)$ & $4.43(-3)$ & $1.46(7)$ & \\
\hline & & & & & & \\
\hline $5 \mathrm{~s}--9 \mathrm{p}$ & $2-2$ & 0.4933 & $8.72(-4)$ & $1.42(-3)$ & $1.11(7)$ & \\
\hline $5 \mathrm{~s}--9 \mathrm{p}$ & $2-4$ & 0.4934 & $1.59(-3)$ & $2.81(-3)$ & $1.10(7)$ & \\
\hline & & & & & & \\
\hline $5 \mathrm{~s}--10 \mathrm{p}$ & $2-2$ & 0.5207 & $5.84(-5)$ & $9.43(-4)$ & $8.20(6)$ & \\
\hline $5 \mathrm{~s}-10 \mathrm{p}$ & $2-4$ & 0.5208 & $1.37(-4)$ & $1.88(-3)$ & $8.20(6)$ & \\
\hline
\end{tabular}


Table 4c. Caption as for Table 4 but for the $3 p^{6} 6 s^{2} S^{e}(\mathrm{~J}=1 / 2)$ state.

\begin{tabular}{|c|c|c|c|c|c|c|c|}
\hline & & & \multicolumn{3}{|c|}{ Present calculations } & \multirow{2}{*}{$\begin{array}{l}\text { Zhang } \\
\text { et al } \\
\text { A-value }\end{array}$} & \multirow{2}{*}{$\begin{array}{l}\text { Ryabtsev } \\
\text { et al } \\
\text { A-value }\end{array}$} \\
\hline & $2 \mathrm{~J}+1$ & $\Delta \mathrm{E}$ & $\mathrm{f}_{1}$ & $f_{v}$ & A-value & & \\
\hline $4 p-6 s$ & $2-2$ & 0.6284 & $2.56(-2)$ & $2.57(-2)$ & $3.26(8)$ & $2.84(8)$ & $3.24(8)$ \\
\hline $4 p-6 s$ & $4-2$ & 0.6247 & $2.60(-2)$ & $2.54(-2)$ & $6.36(8)$ & $5.73(8)$ & $6.35(8)$ \\
\hline $5 p-6 s$ & $2-2$ & 0.1606 & $246(-1)$ & $242(-1)$ & $201(8)$ & $179(8)$ & \\
\hline $5 p-6 s$ & $4-2$ & 0.1591 & $2.50(-1)$ & $2.44(-1)$ & $3.98(8)$ & $3.60(8)$ & \\
\hline $6 s--6 p$ & $2-2$ & $4.046(-2)$ & $5.68(-1)$ & $5.50(-1)$ & $2.89(7)$ & $2.98(7)$ & \\
\hline $6 s--6 p$ & $2-4$ & $4.117(-2)$ & 1.150 & 1.091 & $2.97(7)$ & $3.13(7)$ & \\
\hline $6 s--7 p$ & $2-2$ & 0.1466 & $4.21(-3)$ & $4.67(-3)$ & $3.23(6)$ & & \\
\hline $6 s--7 p$ & $2-4$ & 0.1471 & $7.10(-3)$ & $8.31(-3)$ & $2.89(6)$ & & \\
\hline $6 s--8 p$ & $2-2$ & 0.2094 & $2.91(-3)$ & $3.28(-3)$ & $4.62(6)$ & & \\
\hline $6 s--8 p$ & $2-4$ & 0.2096 & $5.26(-3)$ & $6.20(-3)$ & $4.38(6)$ & & \\
\hline $6 \mathrm{c}-9 \mathrm{n}$ & $2-2$ & 02408 & $165(-3)$ & $108(-3)$ & $307(6)$ & & \\
\hline $6 s--9 p$ & $2-4$ & 0.2499 & $3.02(-3)$ & $3.82(-3)$ & $3.83(6)$ & & \\
\hline $6 s--10 p$ & $2-2$ & 0.2772 & $7.24(-4)$ & $1.25(-3)$ & $3.09(6)$ & & \\
\hline $6 s--10 p$ & $2-4$ & 0.2773 & $1.41(-3)$ & $2.45(-3)$ & $3.03(6)$ & & \\
\hline
\end{tabular}


Table $4 \mathrm{~d}$. Caption as for Table 4 but for the $3 \mathrm{p}^{6} 7 \mathrm{~s}^{2} \mathrm{~S}^{\mathrm{e}}(\mathrm{J}=1 / 2)$ state.

\begin{tabular}{|l|l|l|l|l|l|l|l|}
\hline & & \multicolumn{3}{|c|}{ Present calculations } & \multicolumn{2}{l|}{$\begin{array}{l}\text { Zhang } \\
\text { et al }\end{array}$} & $\begin{array}{l}\text { Ryabtsev } \\
\text { et al }\end{array}$ \\
\hline & $2 \mathrm{~J}+1$ & $\Delta \mathrm{E}$ & $\mathrm{f}_{1}$ & $\mathrm{f}_{\mathrm{v}}$ & A-value & A-value & A-value \\
\hline & & & & & & & \\
\hline $4 \mathrm{p}-7 \mathrm{~s}$ & $2-2$ & 0.7521 & $9.51(-3)$ & $9.70(-3)$ & $1.76(8)$ & $1.62(8)$ & $1.75(8)$ \\
\hline $4 \mathrm{p}-7 \mathrm{~s}$ & $2-4$ & 0.7484 & $9.69(-3)$ & $9.52(-3)$ & $3.43(8)$ & $3.26(8)$ & $3.44(8)$ \\
\hline & & & & & & & \\
\hline $5 \mathrm{p}-7 \mathrm{~s}$ & $2-2$ & 0.2843 & $3.67(-2)$ & $3.61(-2)$ & $9.39(7)$ & $9.97(7)$ & \\
\hline $5 \mathrm{p}-7 \mathrm{~s}$ & $2-4$ & 0.2828 & $3.71(-2)$ & $3.59(-2)$ & $1.85(8)$ & $2.00(8)$ & \\
\hline & & & & & & & \\
\hline $6 \mathrm{p}-7 \mathrm{~s}$ & $2-2$ & $8.326(-2)$ & $3.35(-1)$ & $3.31(-1)$ & $7.38(7)$ & $6.92(7)$ & \\
\hline $6 \mathrm{p}-7 \mathrm{~s}$ & $2-4$ & $8.255(-2)$ & $3.38(-1)$ & $3.33(-1)$ & $1.46(8)$ & $1.39(8)$ & \\
\hline & & & & & & & \\
\hline $7 \mathrm{~s}--7 \mathrm{p}$ & $2-2$ & $2.290(-2)$ & $6.92(-1)$ & $6.78(-1)$ & $1.13(7)$ & & \\
\hline $7 \mathrm{~s}--7 \mathrm{p}$ & $2-4$ & $2.335(-2)$ & 1.408 & 1.332 & $1.17(7)$ & & \\
\hline & & & & & & & \\
\hline $7 \mathrm{~s}--8 \mathrm{p}$ & $2-2$ & $8.571(-2)$ & $3.42(-3)$ & $3.90(-3)$ & $9.22(5)$ & & \\
\hline $7 \mathrm{~s}--8 \mathrm{p}$ & $2-4$ & $8.592(-2)$ & $5.53(-3)$ & $6.83(-3)$ & $8.10(5)$ & & \\
\hline & & & & & & & \\
\hline $7 \mathrm{~s}--9 \mathrm{p}$ & $2-2$ & 0.1260 & $2.52(-3)$ & $3.01(-3)$ & $1.54(6)$ & & \\
\hline $7 \mathrm{~s}--9 \mathrm{p}$ & $2-4$ & 0.1262 & $4.25(-3)$ & $5.67(-3)$ & $1.42(6)$ & & \\
\hline $7 \mathrm{~s}--10 \mathrm{p}$ & $2-2$ & 0.1535 & $6.00(-4)$ & $1.90(-3)$ & $1.43(6)$ & & \\
\hline $7 \mathrm{~s}--10 \mathrm{p}$ & $2-4$ & 0.1536 & $1.43(-3)$ & $3.66(-3)$ & $1.38(6)$ & & \\
\hline
\end{tabular}


Table 4 e. Caption as for Table 4 but for the $3 p^{6} 8 s^{2} S^{e}(J=1 / 2)$ state.

\begin{tabular}{|c|c|c|c|c|c|c|}
\hline & & & \multicolumn{3}{|c|}{ Present calculations } & \multirow{2}{*}{$\begin{array}{l}\text { Ryabtsev } \\
\text { et al } \\
\text { A-value }\end{array}$} \\
\hline & $2 \mathrm{~J}+1$ & $\Delta \mathrm{E}$ & $f_{1}$ & $f_{v}$ & A-value & \\
\hline $4 p-8 s$ & $2-2$ & 0.8237 & $4.61(-3)$ & $4.86(-3)$ & $1.06(8)$ & - \\
\hline $4 p-8 s$ & $2-4$ & 0.8200 & $4.74(-3)$ & $4.75(-3)$ & $2.05(8)$ & $2.08(8)$ \\
\hline $5 p-8 s$ & $2-2$ & 0.3559 & $1.32(-2)$ & $1.32(-2)$ & $5.37(7)$ & \\
\hline $5 p-8 s$ & $2-4$ & 0.3544 & $1.34(-2)$ & $1.31(-2)$ & $1.05(8)$ & \\
\hline $6 \mathrm{p}-8 \mathrm{~s}$ & $2-2$ & 0.1548 & $4.81(-2)$ & $4.78(-2)$ & $3.69(7)$ & \\
\hline $6 p-8 s$ & $2-4$ & 0.1541 & $4.86(-2)$ & $4.72(-2)$ & $7.28(7)$ & \\
\hline $7 p-8 s$ & $2-2$ & $4.865(-2)$ & $4.27(-1)$ & $4.23(-1)$ & $3.23(7)$ & \\
\hline $7 p-8 s$ & $2-4$ & $4.820(-2)$ & $4.31(-1)$ & $4.29(-1)$ & $6.40(7)$ & \\
\hline $8 s--8 p$ & $2-2$ & $1.416(-2)$ & $8.13(-1)$ & $7.76(-1)$ & $5.00(6)$ & \\
\hline $8 s--8 p$ & $2-4$ & $1.437(-2)$ & 1.644 & 1.557 & $5.17(6)$ & \\
\hline $8 s--9 p$ & $2-2$ & $5.449(-2)$ & $3.11(-3)$ & $3.39(-3)$ & $3.23(5)$ & \\
\hline $8 s--9 p$ & $2-4$ & $5.465(-2)$ & $4.37(-3)$ & $6.04(-3)$ & $2.90(5)$ & \\
\hline $8 s--10 p$ & $2-2$ & $8.197(-2)$ & $7.87(-4)$ & $2.91(-3)$ & $6.27(5)$ & \\
\hline $8 s--10 p$ & $2-4$ & $8.203(-2)$ & $2.49(-3)$ & $5.57(-3)$ & $6.02(5)$ & \\
\hline
\end{tabular}


Table 4f. Caption as for Table 4 but for the $3 p^{6} 9 s^{2} S^{e}(J=1 / 2)$ state.

\begin{tabular}{|l|l|l|l|l|l|}
\hline & & \multicolumn{4}{|c|}{ Present calculations } \\
\hline & $2 \mathrm{~J}+1$ & $\Delta \mathrm{E}$ & $\mathrm{f}_{\mathrm{l}}$ & $\mathrm{f}_{\mathrm{v}}$ & A-value \\
\hline & & & & & \\
\hline $4 \mathrm{p}-9 \mathrm{~s}$ & $2-2$ & 0.8687 & $2.55(-3)$ & $2.82(-3)$ & $6.83(7)$ \\
\hline $4 \mathrm{p}-9 \mathrm{~s}$ & $2-4$ & 0.8650 & $2.65(-3)$ & $2.75(-3)$ & $1.32(8)$ \\
\hline & & & & & \\
\hline $5 \mathrm{p}-9 \mathrm{~s}$ & $2-2$ & 0.4008 & $6.39(-3)$ & $6.54(-3)$ & $3.38(7)$ \\
\hline $5 \mathrm{p}-9 \mathrm{~s}$ & $2-4$ & 0.3994 & $6.52(-3)$ & $6.45(-3)$ & $6.61(7)$ \\
\hline & & & & & \\
\hline $6 \mathrm{p}-9 \mathrm{~s}$ & $2-2$ & 0.1998 & $1.71(-2)$ & $1.73(-2)$ & $2.22(7)$ \\
\hline $6 \mathrm{p}-9 \mathrm{~s}$ & $2-4$ & 0.1991 & $1.72(-2)$ & $1.71(-2)$ & $4.36(7)$ \\
\hline & & & & & \\
\hline $7 \mathrm{p}-9 \mathrm{~s}$ & $2-2$ & $9.363(-2)$ & $5.99(-2)$ & $5.99(-2)$ & $1.69(7)$ \\
\hline $7 \mathrm{p}-9 \mathrm{~s}$ & $2-4$ & $9.318(-2)$ & $6.03(-2)$ & $5.97(-2)$ & $3.33(7)$ \\
\hline & & & & & \\
\hline $8 \mathrm{p}-9 \mathrm{~s}$ & $2-2$ & $3.082(-2)$ & $5.11(-1)$ & $5.15(-1)$ & $1.57(7)$ \\
\hline $8 \mathrm{p}-9 \mathrm{~s}$ & $2-4$ & $3.061(-2)$ & $5.18(-1)$ & $5.20(-1)$ & $3.13(7)$ \\
\hline & & & & & \\
\hline $9 \mathrm{~s}--9 \mathrm{p}$ & $2-2$ & $9.51(-3)$ & $9.19(-1)$ & $9.24(-1)$ & $2.69(6)$ \\
\hline $9 \mathrm{~s}--9 \mathrm{p}$ & $2-4$ & $9.67(-3)$ & 1.923 & 1.732 & $2.61(6)$ \\
\hline & & & & & \\
\hline $9 \mathrm{~s}--10 \mathrm{p}$ & $2-2$ & $3.699(-2)$ & $6.67(-4)$ & $2.26(-3)$ & $9.92(4)$ \\
\hline $9 \mathrm{~s}--10 \mathrm{p}$ & $2-4$ & $3.705(-2)$ & $2.52(-3)$ & $5.89(-3)$ & $1.30(5)$ \\
\hline
\end{tabular}


19

Table 4g. Caption as for Table 4 but for the $3 p^{6} 10 \mathrm{~s}^{2} \mathrm{~S}^{\mathrm{e}}(\mathrm{J}=1 / 2)$ state.

\begin{tabular}{|c|c|c|c|c|c|}
\hline & & & \multicolumn{3}{|c|}{ Present calculations } \\
\hline & $2 \mathrm{~J}+1$ & $\Delta \mathrm{E}$ & $f_{1}$ & $\mathrm{f}_{\mathrm{v}}$ & A-value \\
\hline $4 p-10 s$ & $2-2$ & 0.8990 & $1.49(-3)$ & $1.77(-3)$ & $4.60(7)$ \\
\hline $4 p-10 s$ & $2-4$ & 0.8953 & $1.58(-3)$ & $1.73(-3)$ & $8.89(7)$ \\
\hline $5 p-10 s$ & $2-2$ & 0.4311 & $3.53(-3)$ & $3.75(-3)$ & $2.24(7)$ \\
\hline $5 p-10 s$ & $2-4$ & 0.4297 & $3.63(-3)$ & $3.69(-3)$ & $4.38(7)$ \\
\hline $6 p-10 s$ & $2-2$ & 0.2301 & $8.08(-3)$ & $8.45(-3)$ & $1.44(7)$ \\
\hline $6 p-10 s$ & $2-4$ & 0.2294 & $8.21(-3)$ & $8.35(-3)$ & $2.82(7)$ \\
\hline $7 p-10 s$ & $2-2$ & 0.1240 & $2.10(-2)$ & $2.12(-2)$ & $1.05(7)$ \\
\hline $7 p-10 s$ & $2-4$ & 0.1235 & $2.11(-2)$ & $2.11(-2)$ & $2.06(7)$ \\
\hline $8 p-10 s$ & $2-2$ & $6.115(-2)$ & $7.10(-2)$ & $7.08(-2)$ & $8.53(6)$ \\
\hline $8 p-10 s$ & $2-4$ & $6.094(-2)$ & $7.14(-2)$ & $7.07(-2)$ & $1.69(7)$ \\
\hline $9 p--10 s$ & $2-2$ & $2.082(-2)$ & $5.95(-1)$ & $5.98(-1)$ & $8.33(6)$ \\
\hline $9 \mathrm{p}--10 \mathrm{~s}$ & $2-4$ & $2.066(-2)$ & $6.01(-1)$ & $6.06(-1)$ & $1.66(7)$ \\
\hline $10 \mathrm{~s}--10 p$ & $2-2$ & $6.66(-2)$ & 1.095 & $9.36(-1)$ & $1.35(6)$ \\
\hline $10 \mathrm{~s}--10 \mathrm{p}$ & $2-4$ & $6.72(-2)$ & 2.192 & 1.894 & $1.38(6)$ \\
\hline
\end{tabular}


Table 5.The transitions energies $\Delta \mathrm{E}$ (in au) and the length and velocity oscillator strengths $\mathrm{f}_{1}$ and $\mathrm{f}_{\mathrm{v}}$ given by the preliminary calculations in Section 3.1. Using $\Delta \mathrm{E}, \mathrm{f}_{\mathrm{l}}$ and $\mathrm{f}_{\mathrm{v}}$ in ( 6 ) give theoretical transition energies $\Delta E^{t}$ and also in (7) give oscillator strengths $f^{t}$. These calculated values of $\Delta E^{t}$ and $f^{t}$ are compared with the experimental transition $\Delta \mathrm{E}^{\mathrm{e}}$ and calculated oscillator strengths $\mathrm{f}_{\mathrm{v}}^{\mathrm{c}}$ given in Tables $4 \mathrm{a}, \mathrm{b}, \mathrm{c}, \mathrm{d}, \mathrm{e}, \mathrm{f}$, and $\mathrm{g}$ for $2-2$ transitions.

\begin{tabular}{|l|l|l|l|l|l|l|l|l|}
\hline Transition & $2 \mathrm{~J}+1$ & \multicolumn{1}{|c|}{$\mathrm{f}_{\mathrm{l}}$} & $\mathrm{f}_{\mathrm{v}}$ & $\Delta \mathrm{E}^{\mathrm{t}}$ & $\Delta \mathrm{E}^{\mathrm{e}}$ & $\mathrm{f}^{\mathrm{t}}$ & $\mathrm{f}_{\mathrm{v}}^{\mathrm{c}}$ \\
\hline & & & & & & & & \\
\hline $4 \mathrm{~s}-4 \mathrm{p}$ & $2-2$ & 0.23648 & 0.3089 & 0.2434 & 0.2099 & 0.2166 & 0.270 & 0.268 \\
\hline $5 \mathrm{~s}-5 \mathrm{p}$ & $2-2$ & 0.10420 & 0.5576 & 0.3400 & 0.08136 & 0.08293 & 0.435 & 0.429 \\
\hline $6 \mathrm{~s}-6 \mathrm{p}$ & $2-2$ & 0.06148 & 0.8619 & 0.3592 & 0.03965 & 0.04046 & 0.556 & 0.550 \\
\hline $7 \mathrm{~s}-7 \mathrm{p}$ & $2-2$ & 0.04386 & 1.3266 & 0.3474 & 0.02245 & 0.02290 & 0.679 & 0.678 \\
\hline $8 \mathrm{~s}-8 \mathrm{p}$ & $2-2$ & 0.03511 & 2.015 & 0.3120 & 0.01382 & 0.01416 & 0.793 & 0.776 \\
\hline $9 \mathrm{~s}-9 \mathrm{p}$ & $2-2$ & 0.03033 & 3.023 & 0.2709 & 0.00908 & 0.00951 & 0.904 & 0.924 \\
\hline $10 \mathrm{~s}-10 \mathrm{p}$ & $2-2$ & 0.02751 & 4.502 & 0.2270 & 0.00618 & 0.00666 & 1.011 & 0.936 \\
\hline & & & & & & & & \\
\hline $4 \mathrm{p}-5 \mathrm{~s}$ & $2-2$ & 0.36900 & 0.1483 & 0.1648 & 0.3890 & 0.3849 & 0.156 & 0.158 \\
\hline $5 \mathrm{p}-6 \mathrm{~s}$ & $2-2$ & 0.13942 & 0.2132 & 0.2787 & 0.1594 & 0.1606 & 0.244 & 0.242 \\
\hline $6 \mathrm{p}-7 \mathrm{~s}$ & $2-2$ & 0.06203 & 0.2484 & 0.4435 & 0.08288 & 0.08326 & 0.332 & 0.331 \\
\hline $7 \mathrm{p}-8 \mathrm{~s}$ & $2-2$ & 0.02755 & 0.2407 & 0.7476 & 0.04855 & 0.04865 & 0.424 & 0.423 \\
\hline $8 \mathrm{p}-9 \mathrm{~s}$ & $2-2$ & 0.009915 & 0.1642 & 1.598 & 0.03093 & 0.03082 & 0.512 & 0.515 \\
\hline $9 \mathrm{p}-10 \mathrm{~s}$ & $2-2$ & $1.092(-4)$ & $3.113(-3)$ & $1.140(2)$ & 0.02089 & 0.02082 & 0.596 & 0.598 \\
\hline
\end{tabular}

